\title{
Key factors of the human capital management in view of digital transformation
}

\author{
Valentin Nikonorov \\ The graduate school \\ of management and business \\ Peter the Great St.Petersburg \\ Polytechnic University \\ St. Petersburg, Russia \\ nikanorv@mail.ru
}

\author{
Victor Tutukin \\ Department of economic cybernetics \\ St. Petersburg State University \\ St. Petersburg, Russia \\ vktutukin@mail.ru
}

\begin{abstract}
Digitalization - the use of innovative digital technologies in all spheres of human activity - is indispensable condition for the country's competitiveness. In the same way, human capital is the main driver of economic growth in the country. The purpose of the research is to reveal factors of management of the human capital. In the process of research, the modern vision of human capital particularly special human capital was studied as a form of labor. The economicmathematical model of the human capital is constructed. The solution of the received economic-mathematical model of the human capital is proposed.
\end{abstract}

Keywords-human capital, digitalization, economy of knowledge, education, skills, health.

\section{INTRODUCTION}

The main contribution to the gross domestic product of the country comes from economy of knowledge ( for example the contribution is $45 \%$ of GDP in the USA). The economy of knowledge is customary a complex of such industries as science, education, information technology, biotechnology, and medicine. The knowledge economy is involved in the production and dissemination of knowledge. [1].

It is not much of an exaggeration to say that human capital is the key driver of economy of knowledge ,which was intensified with such lever as digitalization many times. S. Kuznets the founder of the theory of economic growth believed that the main reason for the country's economic growth was human capital. [2]

There are issues of optimal conjugation of human capital and digitalization. The answer to these questions will allow you to choose the best ways for the further development of the knowledge economy and, accordingly, for the further growth of GDP. It is quite relevant for the Russian economy, since the share of the knowledge economy in our country does not exceed 20\%. While Russia lags behind developed countries in investments in the knowledge economy. (table 1)
TABLE 1. INVESTMENTS IN THE BRANCHES OF THE ECONOMIC KNOWLEDGE

\begin{tabular}{|c|c|c|c|}
\hline \multirow{2}{*}{ № } & \multirow{2}{*}{$\begin{array}{l}\text { Branch of economic } \\
\text { knowledge }\end{array}$} & \multicolumn{2}{|c|}{$\begin{array}{l}\text { Investments in the } \\
\text { industry, } \% \text { of GDP }\end{array}$} \\
\hline & & $\begin{array}{c}\text { Countries } \\
\text { G7* }\end{array}$ & Russia \\
\hline 1 & $\begin{array}{l}\text { Research, Development and } \\
\text { Engineering }\end{array}$ & $2,5 \%$ & $1,1 \%$ \\
\hline 2 & Education & $6,0 \%$ & $3,5 \%$ \\
\hline 3 & $\begin{array}{l}\text { Health Service and } \\
\text { biotechnologies }\end{array}$ & $12,0 \%$ & $4,0 \%$ \\
\hline 4 & $\begin{array}{l}\text { Information and } \\
\text { communication technology }\end{array}$ & $8,5 \%$ & $2,0 \%$ \\
\hline 5 & Total "knowledge economy" & $29,0 \%$ & $10,6 \%$ \\
\hline
\end{tabular}

The term human capital, in its modern sense, was introduced into scientific circulation by Theodore-William Schultz. [4] By human capital, he considered the following human skills as:

1) necessary for productive labor;

2) can be itensified through investment (primarily in education)

G. Becker considered human capital as such a sum of human implicit abilities, acquired knowledge, skills, motivations, which, if used effectively, will allow the owner of human capital to increase their income. [5]

Accordingly, G. Becker considered not only education, but also vocational training in production, health care expenses, etc as an investment in human capital. Also G. Becker defined the forms of manifestation of human capital: general knowledge, special knowledge (special human capital), other knowledge. The most important for the production of goods and services are special knowledge, they can be assimilated to the sum of skills and abilities of a particular sphere professional working in the organization.[6,7] The human capital is ability to produce things and services.

Special human capital (further as SHC) works on the specific enterprise (the same where the owner of SHC works) accordingly, generates income to the country of which the owner of the special human capital resides. 
"The art of mechanics is not wealth which is added to the human: the" skilled mechanic "must be classified as wealth as itself" [8]

Representatives of institutionalism (C. Lankaster, M. Will, R. Willis, and others) identified the role of the social environment and social relations in the human capital formation. [9] Consequently, the social origin influences the formation of the SHC, determining access to sound academic background. Of course, the factor of health of the owner of the SHC also has an effect: the better the health, the more opportunities for the formation of the SHC and its subsequent use.

It can be assumed that special human capital is inextricably linked with human intelligence, and the connection is direct and fairly strong. As one of the confirmations, it is possible to cite the fact that the level of income (benefit from SHC) directly depends on the mathematical abilities (intelligence). [10]

We give a trivial chain: abstraction - the basic process of mental activity (inherent only to humans); the highest level of abstraction (high intelligence) in mathematics. Parallel lets add the fact that the export from India of offshore programming (mathematical programs) exceeds the export of gas, ferrous and non-ferrous metals from Russia. [3]

Although the Russian level of mathematical education is higher than the Indian, so the government took care of it and required with the decree of the President of the Russian Federation to create network of international mathematical centers until 2024. [11]

Probably, to obtain a good education requires certain natural capabilities (genetic potential).

But consideration of this direction is fraught with (social Darwinism, eugenics, etc.). There is also no doubt that in order to generate income from the SHC, the owner of the SHC must work (financial capital can grow even without labor costs - a rentier)

According to the authors thoughts, SHC is one of the forms of labor, the most important factor of production. That is, it can be assumed that labor in production (labor in housekeeping is not considered here) is come out in the forms as:

1) Labor. In this case, the limits of the skills and knowledge of the employee sets the means of labor. A car for the driver, a machine for the machine operator, etc .;

2) SHC. The means of labor is directly the owner's intelligence.

SHC .The labor limits are given by the owner's brain.

Let's emphasize the main factors influencing the SHC formation according to the authors:

1) education - creates education capital;

2) production experience - creates labor capital;

3) health - creates health capital;

4) social origin -creates ,so to say, social capital.
Thus, the authors identified the elements of special human capital. All of them are inalienable from the owner of SHC.

Note that Russia has perspectives for growth in terms of human capital. (Table 2).

TABLE 2. HUMAN CAPITAL INDEX (HCI)
\begin{tabular}{|c|c|c|}
\hline № & Countries & HCI \\
\hline 1 & Singapore & 0,88 \\
\hline 2 & South Korea & 0,84 \\
\hline 3 & Japan & 0,84 \\
\hline 4 & Hong Kong & 0,82 \\
\hline 5 & Finland & 0,81 \\
\hline 6 & Ireland & 0,81 \\
\hline 7 & Australia & 0,80 \\
\hline 8 & Sweden & 0,80 \\
\hline 9 & The Netherlands & 0,80 \\
\hline 10 & Canada & 0,80 \\
\hline 11 & Germany & 0,79 \\
\hline 12 & Austria & 0,79 \\
\hline$\ldots$ & & \\
\hline 34 & Russia & 0,73 \\
\hline
\end{tabular}

There is a strong direct connection between the human capital index and the level of education. To this thought summarizes the data table.3.

TABLE 3. EDUCATION LEVEL INDEX (EI)

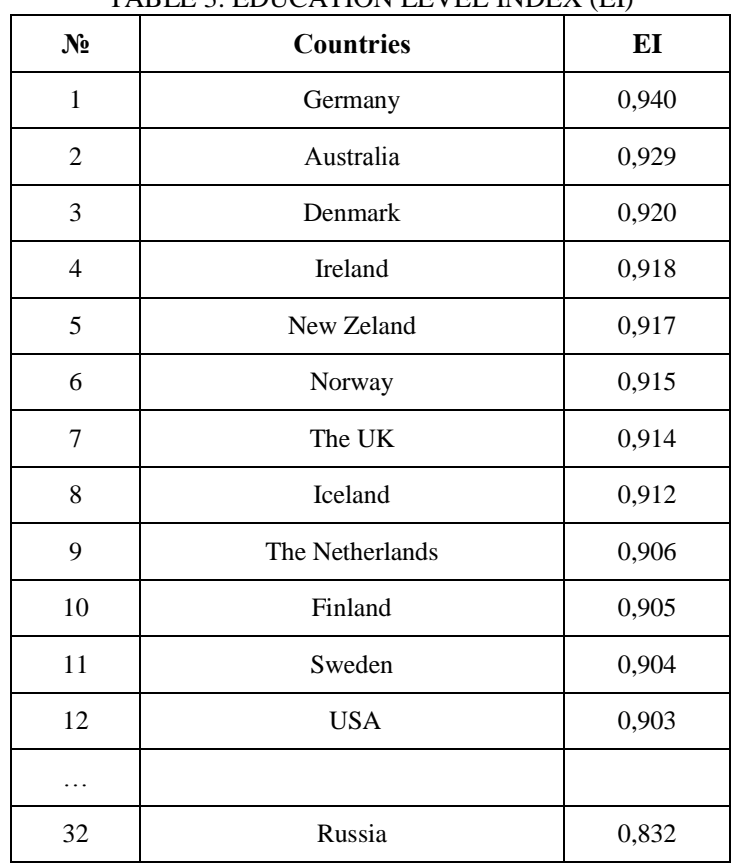

It can be assumed that Soviet education played a positive role in the value of the Russian human capital index. The current 33rd place can be explained if the data of Table 1 is remembered (investments in the industry are two times less 
than in G7 countries). It is education that is the main factor for the formation of human capital.

Having considered the main features of SHC, let's get down to digitalization. According to the authors, digitalization can be understood as the development and implementation of digital technologies of accumulation, processing, transportation, storage, retrieval and visualization of data in all industries. The main effect of digitalization is the simplification and acceleration of business processes, increasing the accuracy and quality of work .Effect shows:

1) reduction of production and financial cycles;

2) optimization of production costs;

3) increase in labor productivity;

4) improving product quality;

5) profit maximization.

Since the main goal of a market economy is to make a profit, you can not worry about further accelerated development of digitalization. Danish researcher Jens Rasmussen divided all professions into 3 categories [14]

1) skill - low-skilled physical labor (driver, loader);

2) rule - strict fulfillment of job descriptions (nurse, accountant);

3) knowledge - more than $50 \%$ of tasks require an analytical and creative approach under conditions of uncertainty, respectively, of high-quality education (doctor, engineer).

According to BCG (Boston Consulting Group) in the most developed countries (USA, Japan, Singapore, South Korea, Germany, UK) more than $25 \%$ of employees work in the "Knowledge" category. [15]

Further development of digitalization will lead to the fact that employees of the categories "Skill", "Rule" will be replaced by robots, new professions from the category "Knowledge" will appear (for example, a mechanic for robots, a biologist on growing bio-engineering organs, etc.).

Moreover, new professions will become increasingly difficult. The economic effect of such a substitution according to BCG for Russia will be $+1.5 \%$ of GDP per year. But workers expelled by robots will become "redundant people." According to the World Bank, in the US, jobreplacement risk ranges from 7 to $47 \%$, in Japan from 6 to 55.

According to the Skolkovo Moscow School of Law, the "Atlas of New Professions". 186 new professions will appear in Russia, 57 will die project by 2030.

The onset of digitalization is inevitable; it remains to assess the possible consequences of this study. What are the pros and cons of digitization for the formation of SHC? Let's take into consideration the factors influencing the formation of SHC.

1) Education. The possibility of genetic editing and genetic modification of the species Homo sapiens (the result will be, for example, Homo sapiens evolutus) is not excluded in order to improve the genetic fund and improve the quality of workers in the category "Knowledge".
After such an invasion of the human body, the descendants of the categories "Skill", "Rule" can go into the category "Knowledge". In general, this can lead to biological inequality, which is more radical than social inequality.

But SHC may increase many times. For other workers, the need to constantly change jobs (the death of some professions and the emergence of new ones) will lead to a decrease in motivation to education.

2) Production experience. There may be difficulties. New professions can appear at high speed (15 professions per year - "Atlas of new professions). Consulting company Deloitte believes that in the digital epoch, career and education should go in real time and on an ongoing basis.[16] «Deloitte» also assumes that a new type of leader is needed to manage the organization of the future - a digital leader, a person who forms and develops a digital culture in his organization.

So, the operational training of teachers will be required in they train qualified staff. There is a risk of the disappearance of the profession as itself by the time of the preparation of a highly qualified teacher. Also, learning a new complex profession may require a certain sorting of trainees according to their level of intelligence. A sort of targeting to get the most benefit from learning.

3) Health. Since we have already mentioned "a biologist on growing bioengineering bodies" in the list of new professions, the health of the owner of the SHC may also be subject to adjustment in the direction of improvement. That can increase the life of the SHC, since the death of the owner causes the SHC to be reset (there is no labor and no income from the SHC).

Moreover, if it becomes possible to combine human and artificial intelligence (implanting gadgets into the human body), then the person will become one of the many elements of the "Industrial Internet of Things" IIoT (Industrial Internet of Things), assimilate to objects. It poses a question about the beneficiaries of such a system.

4) Social inequality can be replaced by biological inequality. Instead of one obstacle on the way to education, another but higher will appear.

\section{THE MODEL}

How to define management of the human capital? Let's apply the model Solow to one-sector economy. Let's consider it for production of the human capital with a number of simplifications. [17]

$$
\begin{aligned}
& Y=A E^{\alpha} R^{\beta} \\
& \mathrm{Y}=\mathrm{I}+\mathrm{C} \\
& \frac{d R}{d t}=-\mu R+I
\end{aligned}
$$

And - coefficient of technologies. It is supposed that this constant. For this model this coefficient can consider, for example, effect of training of workers at production. Direct introduction of effect of training of workers at production would complicate (1). 
$\alpha=\beta=0.5$. This simplification will allow to solve economic-mathematical model. If $\alpha \neq \beta$, the decision in an analytical look not to receive.

Y - the cost of the human capital, the work of the average salary on number of busy. It is the lower estimation of cost of the human capital. Production function of CobbDouglas [18] is applied/

E - expenses for education in the country. Growth of expenses for education increases the human capital. Education provides transfer of the accumulated knowledge to the subsequent generations. Without this transfer there would be no growth of the human capital.

$\mathrm{R}$ - expenses on research and development, reflect a digitalization contribution. By analogy with function of Cobb-Douglas, it is expenses on the non-material capital. Research and development leads to growth of knowledge. As they are shown in finished goods, they cannot be kept within one firm. Respectively, results of research and development are distributed among all human capital. Digitalization determines the speed of dissemination of the obtained data. The more progress of digitalization, the quicker is imparted the new knowledge gained as a result of research and development.

I - investments into education;

$\mu$ - wear of intangible assets;

$\mathrm{C}$ - expenses on reproduction of the human capital.

(1) - production of the human capital;

(2) - expenditure of the human capital;

(3) - dynamics of expenses on research and development.

According to authors the system of the equations (1)-(3) sets as a first approximation economic-mathematical model of the human capital. In this economic-mathematical model the human capital is defined by expenses for education and expenses on research and development. According to authors these factors can be applied to assessment of the impact on growth of the human capital. The demographic aspect is not considered for simplicity of economic-mathematical model.

Let's transfer the received economic-mathematical model to specific indicators. For this purpose we will divide all elements of economic-mathematical model into $\mathrm{Y} 0$, cost of the human capital during the set initial stage of time. We choose Y0 taking into account the available statistics.

$$
\begin{aligned}
& y=A e^{\frac{1}{2}} r^{\frac{1}{2}} \\
& \mathrm{y}=\mathrm{i}+\mathrm{c} \\
& \frac{d r}{d t}=-\mu r+i
\end{aligned}
$$

Let's assume that specific expenses for education of $\mathrm{e}=$ const. As first of all we are interested in influence of costs of research and development on the human capital. Let's carry out the corresponding transformations.

$$
r=\frac{y^{2}}{A^{2} e}
$$

$$
\begin{aligned}
& \frac{2 y y^{\prime}}{A^{2} e}+\frac{\mu y^{2}}{A^{2} e}-y+c=\mathbf{O} \\
& A^{2} e=b \\
& 2 y y^{\prime}+\mu y^{2}-b y+b c=0
\end{aligned}
$$

According to authors, the differential equation (7) is economic-mathematical model of growth of the human capital.

$$
\begin{aligned}
& \frac{d y}{d \tau}=\frac{-\mu y^{2}+b y-b c}{2 y} \\
& \frac{2 y d y}{\left(-\mu y^{2}+b y-b c\right)}=d \tau \\
& D=\sqrt{b^{2}-4 \mu b c} \\
& \left(D y+\frac{b(b+D)}{2 \mu} \ln \left|y-\frac{b+D}{2 \mu}\right|-\frac{(b-D)^{2}}{2 \mu} \ln \left|y-\frac{b-D}{2 \mu}\right|=-\frac{\mu D}{4} \tau+C 1\right.
\end{aligned}
$$

It is a formal dynamic system. The received result allows to be a simulation model and to count it on the computer. Respectively, it is possible to calculate as the concrete factor influences growth of the human capital. The model can seem obvious, the main advantage in allocation of quantitatively significant effects.

Statistical researches will allow to estimate model parameters A, e, b, c.

\section{CONCLUSION}

The results of the research.

1) The modern vision of human capital has been studied. The most important element for the production of human capital - special human capital - has been identified.

2) Forms of labor labor itself and special human capital were emphasized.

3) The factors influencing the formation of SHC were concerned.

4) The possible impact of digitalization on SHC was indicated.

5) The economic-mathematical model of cost of the human capital is constructed and solved.

\section{REFERENCES}

[1] Machlup F. The Production and Distribution of Knowledge in the United States. New Jersey: Princeton University Press, 1980.

[2] Kuznets Simon S. Long swings in the growth of population and in related economic variables // Proceedings of the American philosophical society. 1958. Vol.102. №1: P. 25-52

[3] Aganbegyan A.G. Socio-economic development of Russia // Massenger of the Bashkir University. 2015. T.20. №2, c.490-493.

[4] Schultz T.W. Investment in Human Beings. - Chicago: University of Chicago Press, 1962.

[5] Becker G. S. Investment in Human Capital: A. Theoretical Analysis // Journal of Politikal Economy. Supplement. Oct., 1962 
[6] Kalinina, O.V., Zaychenko, I.M., Gutman, S.S. Concept of creating innovative mechanism of human resource development in Russia (2017) 2017-January, pp. 2708-2719.

[7] Ilin, I., Shirokova, S., Lepekhin, A. IT Solution concept development for tracking and analyzing the labor effectiveness of employees (2018) E3S Web of Conferences, 33, 03007.

[8] Thurou L. Investment in Human Capital. Belmont, 1970, P. 116-117.

[9] Fisher I. The Nature of Capital and Income. N. Y., 1975.

[10] Lancaster K. Changes and Innovation in Consumer Technology // Milestones in Economic Thought. SPb .: School of Economics, 2000. $-380 s$.

[11] Eckaus R. S. Estimation of the Returns to Education with Hourly Standartized Income // Quortely Journal of Economics. 1973. V. 87. P. 127.

[12] On the national goals and strategic objectives of the development of the Russian Federation for the period up to 2024. Presidential Decree of May 7, 2018. No. 204. [Electronic resource]. - Access mode: https://minenergo.gov.ru/view-pdf (access date: 06/28/2019)

[13] Word Development Report 2019 [Electronic resource]. - Access mode:

http://documents.worldbank.org/curated/en/816281518818814423/pdf (access data: 28.06.2019)
[14] Human Development Reports 2018 [Electronic resource]. - Access mode: http://hdr.undp.org/en/content/education-index (access date: 28.06.2019)

[15] J. Rasmussen. Skills, Rules, and Knowledge; Signals, Signs, and Symbols, and other distinctions in Human Performance models// IEEE Transaction Systems, Man and Cybernetics. 1983. V.13. P. 257266

[16] Russia 2025: from workers to talents [Electronic resource]. - Access mode: https://www.bcg.com/ru-ru/default.aspx. (access date: 28.06.2019)

[17] Atlas of new professions [Electronic resource]. - Access mode: https://www.skolkovo.ru/public/media/documents/research/sedec. (access date: 28.06.2019)

[18] New rules of digital epoch game. [Electronic resource]. - Access mode:

https://www2.deloitte.com/content/dam/Deloitte/ru/Documents/huma n-capital (access date: 28.06.2019)

[19] Solow R.M. Contribution to the theory of economic growth // Quarterly journal of economics. - 1956. - V.70 - P. 65-94.

[20] Cobb W. Douglas P.H. A theory of production // The American Economic Review. Vol.18. №1. 